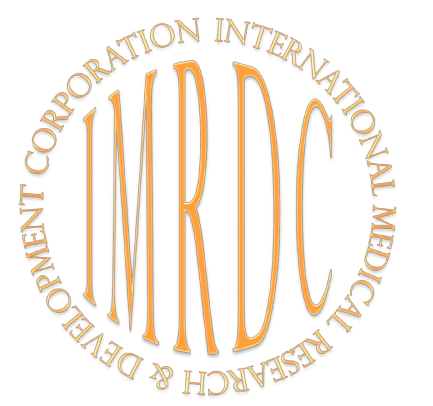

\title{
Impact of Metabolic Syndrome Components on Asthma Control and Life Quality of Patients
}

\author{
Andrey V. Budnevsky, PhD, ScD; Ludmila V. Tribuntceva, PhD; \\ Svetlana A. Kozhevnikova, PhD; Evgeniy S. Ovsyannikov, PhD* \\ Voronezh State Medical University named after N.N. Burdenko \\ Voronezh, the Russian Federation
}

\begin{abstract}
The purpose of this study was to assess the characteristics of the clinical course of asthma in patients with metabolic syndrome (MetS) and to analyze the influence of the MetS components on the course of asthma, control of asthma symptoms, and the the quality of life (QL) of patients with asthma.

Materials and Methods: We examined 95 asthma patients aged from 18 to 60 years. The patients were divided into 2 groups. Group 1 included 35 patients without MetS (24/68.6\% women and 11/31.4\% men; mean age, 49.81 \pm 0.77 years), and Group 2 included 60 patients with MetS (45/75.0\% women and 15/25.0\% men; mean age, $49.82 \pm 0.77$ years). The asthma diagnosis was based on the integral assessment of symptoms, medical history, health status, and spirometry values according to the Global Strategy for Asthma Management and Prevention (2017). MetS was diagnosed according to the IDF consensus criteria (2006).

Results: The MetS components, such as central obesity, high blood pressure, dyslipidemia, carbohydrate metabolism disorder, cause a more serious and unfavorable course of asthma, with frequent exacerbations, calls to emergency service and hospital admissions, severe asthma symptoms, uncontrolled asthma symptoms, low spirometry results, and low level of QL in the physical and psychological domains. (International Journal of Biomedicine. 2018;8(1):33-36.)
\end{abstract}

Key Words: asthma $\bullet$ metabolic syndrome $\bullet$ uncontrolled asthma symptoms $\bullet$ quality of life

\section{Abbreviations}

BP, bodily pain; BMI, body mass index; $\mathbf{C O}$, central obesity; $\mathbf{F E V}$, forced expiratory volume in $1 \mathrm{sec} ; \mathbf{F P G}$, fasting plasma glucose; FVC, forced vital capacity; FEF, forced expiratory flow; GH, general health; HDL-C, high-density lipoprotein cholesterol; MetS, metabolic syndrome; MH, mental health; OGTT, oral glucose tolerance test; PEF, peak expiratory flow; PF, physical functioning; QL, the quality of life; RP, role-physical functioning; RE, role emotional; SF-36, the 36-Item Short-Form Health Survey; SF, social functioning; TG, triglycerides; VC, vital capacity; VT, vitality; VAS, the 10-point Visual Analogue Scale; WC, waist circumference.

\section{Introduction}

Asthma and MetS have a considerable impact on public health, and their prevalence has increased in recent years..$^{(1)}$ Numerous studies have linked these disorders. The presence

*Corresponding author: Evgeniy S. Ovsyannikov, PhD. Department of faculty therapy, Voronezh State Medical University named after N.N. Burdenko. Voronezh, the Russian Federation. E-mail: ovses@yandex.ru of complex, multiple pathogenetic links in these nosological forms is emphasized, which in most cases leads to the formation of the phenomenon of mutual burdening, limiting the achievement of a controlled course of asthma on the one hand, and increasing the risk of developing diabetes mellitus and cardiovascular diseases on the other. ${ }^{(2)} \mathrm{WHO}$ estimates that 235 million people currently suffer from asthma. Asthma is the most common noncommunicable disease among children. According to the latest WHO estimates, released in December 2016, there were 383000 deaths due 
to asthma in 2015. ${ }^{(3)}$ The number of severe and late-onset forms of asthma is increasing; the incidence of disability due to asthma is about $2.0 \%$ of cases. ${ }^{(4)}$ The disease reduces life expectancy by an average of 7 years for men, 15 years for women. ${ }^{(5)}$

Worldwide, there has been a significant increase in the number of patients with MetS - up to $15 \%-25 \%$ of the adult population - which is associated with the high prevalence of obesity in the world. ${ }^{(6)}$ The increase in MetS is reflected primarily in the increased prevalence of such diseases as diabetes, as well as diseases associated with dyslipidemia and atherosclerosis (ischemic heart disease, cerebrovascular disease, arterial hypertension). At the same time, the association between MetS and the index of total mortality from cardiovascular diseases is becoming more and more evident.(7)

In recent years, the question of the influence of MetS components on the course of asthma has been increasingly studied, and the features of the combined course of these nosological forms are also being studied. ${ }^{(8)}$

It has been found that improvement of living conditions (easy access to more food) contributes to the growth of both obesity and asthma. Obesity promotes the development of bronchial hyperreactivity caused by physical exertion in patients with asthma. ${ }^{(9)}$

Arterial hypertension is associated with asthma development. This association can be considered as a cardio-pulmonary problem because of close anatomical and functional relations between these two systems. ${ }^{(10)}$

Disorders of lipid metabolism and risk of asthma development are based on common risk factors, such as lack of adequate physical activity, sedentary life style, improper feeding, environmental influence, and psychoemotional stress. (11) Possible association between asthma and carbohydrate metabolism disorder can also be explained by lack of adequate physical activity and improper feeding. ${ }^{(12)}$

In the available literature, there are inconsistent, insufficient data on the relationship between the degree of severity of the MetS components and the features of clinical and instrumental indicators of asthma, the level of disease control, and QL of asthma patients.

The purpose of this study was to assess the characteristics of the clinical course of asthma in patients with MetS and to analyze the influence of the MetS components on the course of asthma, control of asthma symptoms, and the QL of patients with asthma.

\section{Materials and Methods}

We examined 95 asthma patients aged from 18 to 60 years. The patients were divided into 2 groups. Group 1 included 35 patients without MetS (24/68.6\% women and $11 / 31.4 \%$ men; mean age, $49.81 \pm 0.77$ years), and Group 2 included 60 patients with MetS $(45 / 75.0 \%$ women and $15 / 25.0 \%$ men; mean age, $49.82 \pm 0.77$ years). The asthma diagnosis was based on the integral assessment of symptoms, medical history, health status, and spirometry values according to the Global Strategy for Asthma Management and Prevention. ${ }^{(13)}$ MetS was diagnosed according to the
IDF consensus criteria. According to the new IDF definition (2006), the MetS is present when WC is increased ( $\geq 94 \mathrm{~cm}$ in males and $\geq 80 \mathrm{~cm}$ in females (for Europids)) and at least two of the following factors are present: raised TG ( $\geq 1.7 \mathrm{mmol} / 1$ or specific treatment for this lipid abnormality); reduced HDL-C $(<1.03 \mathrm{mmol} / 1$ in males and $<1.29 \mathrm{mmol} / 1$ in females or specific treatment for this lipid abnormality); systolic blood pressure $\geq 130 \mathrm{mmHg}$ or diastolic blood pressure $\geq 85 \mathrm{mmHg}$ or treatment of previously diagnosed hypertension; raised FPG ( $\geq 5.6 \mathrm{mmol} / \mathrm{l})$ or previously diagnosed type 2 diabetes. ${ }^{(14)}$

The study was approved by the Ethics Committee of Voronezh State Medical University named after N.N. Burdenko. Written informed consent was obtained from each patient.

A comprehensive clinical examination and laboratory tests included the following procedures:

- Anthopometrical reference data: BMI was calculated using Quetelet's formula (in $\mathrm{kg} / \mathrm{cm}^{2}$ ). WC was measured using centimetric tape at the navel level on a horizontal line (in $\mathrm{cm}$ )

- Assessment of asthma severity included the number of exacerbations, calls to emergency service and hospital admissions for the past 12 months.

- Quantity assessment of asthma symptoms (dyspnea, chest tightness, cough, sputum) by VAS.

- Assessment of asthma symptoms control by Asthma Control Test ${ }^{\mathrm{TM}}(\mathrm{ACT})$

- Functional tests: spirometry

- Assessment of QL by SF-36

- Assessment of BP by Korotkov's method.

- Assessment of FPG, OGTT, and blood levels of TG and HDL-C.

All data was evaluated with STATGRAPHICS Plus 5.1. Baseline characteristics were summarized as frequencies and percentages for categorical variables and as mean $\pm \mathrm{SD}$ for continuous variables. Student's unpaired t-test was used to compare two groups for data with normal distribution. A probability value of $P<0.05$ was considered statistically significant.

\section{Results and Discussion}

According to clinical examination results, $60 / 63.2 \%$ patients with asthma had MetS:

- CO plus high level of TG plus low HDL-C in 8/13.3\% patients

- CO plus high BP plus high level of FPG in 29/48.3\% patients

- CO plus high TG plus low HDL-C plus high FPG in $7 / 11.7 \%$ patients

- CO plus high BP plus high TG plus low HDL-C in $16 / 26.7 \%$ patients

A comprehensive clinical examination demonstrated statistically significant differences in assessment parameters between Groups 1 and 2. In Group 2, the number of asthma exacerbations was 1.6 times greater $(3.50 \pm 0.11$ vs. $2.20 \pm 0.13$ per year, $P=0.000$ ), calls to emergency service -1.4 times greater $(2.83 \pm 0.08$ vs. $2.03 \pm 0.12$ per year, $P=0.000)$, and hospital admissions - 1.3 times greater $(1.82 \pm 0.08$ and 
$1.37 \pm 0.10$ per year, $P=0.0007$ ) compared to Group 1 .

There were significant differences in subjective assessment of asthma symptoms between Group 1 and 2, according to the 10-point Visual Analogue Scale. In Group 2, patients' dyspnea intensity was 1.8 times greater $(5.85 \pm 0.13$ vs. $3.29 \pm 0.10, P=0.000)$, chest tightness intensity -1.5 times greater $(3.07 \pm 0.10$ vs. $2.03 \pm 0.22, P=0.000)$, cough intensity - 1.6 times greater ( $4.30 \pm 0.13$ vs. $2.68 \pm 0.16, P=0.000)$, and sputum intensity - 1.5 times greater $(3.68 \pm 0,11$ vs. $2.48 \pm 0,19$, $P=0.000)$ compared to Group 1 .

All patients with asthma and MetS had uncontrolled asthma symptoms. There were significant ACT value differences between Group 1 and 2: $17.03 \pm 0.54$ and $13.58 \pm 0.32$ $(P=0.0000)$.

Spirometry results were also significantly different between Group 1 and Group 2 (Table 1).

Table 1.

Spirometry parameters in two groups

\begin{tabular}{|l|c|c|}
\hline \multicolumn{1}{|c|}{ Variable } & Group 1 & Group 2 \\
\hline FVC, $\%$ of predicted & $70.07 \pm 2.48$ & $60.55 \pm 0.58^{*}$ \\
\hline VC, $\%$ of predicted & $71.13 \pm 0.42$ & $63.01 \pm 0.36^{*}$ \\
\hline FEV $_{1}, \%$ of predicted & $73.82 \pm 0.64$ & $65.05 \pm 1.21^{*}$ \\
\hline FEV1/FVC, \% & $78.59 \pm 0.53$ & $70.79 \pm 1.48^{*}$ \\
\hline PEF, \% of predicted & $54.23 \pm 1.21$ & $46.81 \pm 0.77^{*}$ \\
\hline $\mathrm{FEF}_{75} \%$ of predicted & $49.47 \pm 1.82$ & $41.11 \pm 0.94^{*}$ \\
\hline $\mathrm{FEF}_{50} \%$ of predicted & $51.79 \pm 0.58$ & $43.73 \pm 1.71^{*}$ \\
\hline $\mathrm{FEF}_{25} \%$ of predicted & $65.75 \pm 0.67$ & $56.09 \pm 1.39^{*}$ \\
\hline
\end{tabular}

$*_{-} P<0.05$

Patients in Group 2 demonstrated a low level of QL in the physical and psychological domains, according to SF-36, in comparison with Group 1 (Table 2).

Table 2.

$S F-36$ parameters in two groups

\begin{tabular}{|c|c|c|}
\hline Variable & Group 1 & Group 2 \\
\hline PF & $75.74 \pm 1.77$ & $59.67 \pm 1.61^{*}$ \\
\hline RP & $56.54 \pm 1.98$ & $43.50 \pm 1.59^{*}$ \\
\hline BP & $63.66 \pm 1.86$ & $47.97 \pm 1.53^{*}$ \\
\hline GH & $58.28 \pm 1.99$ & $45.35 \pm 1.41^{*}$ \\
\hline VT & $67.46 \pm 2.05$ & $51.80 \pm 1.64^{*}$ \\
\hline SF & $65.69 \pm 2.21$ & $50.08 \pm 1.28^{*}$ \\
\hline RE & $60.80 \pm 2.17$ & $53.02 \pm 1.35^{*}$ \\
\hline MH & $73.29 \pm 2.01$ & $63.70 \pm 1.47^{*}$ \\
\hline PF & $75.74 \pm 1.77$ & $59.67 \pm 1.61^{*}$ \\
\hline
\end{tabular}

$*_{-} P<0.05$
The performed correlation analysis between the indicators characterizing the clinical course of asthma, the level of control over the disease, and the QL of asthma patients with MetS components revealed statistically significant values of correlation coefficients. The MetS components, such as central obesity, high blood pressure, dyslipidemia, carbohydrate metabolism disorder, cause a more serious and unfavorable course of asthma, with frequent exacerbations, calls to emergency service and hospital admissions, severe asthma symptoms (dyspnea, chest tightness, cough with sputum), uncontrolled asthma symptoms, low spirometry results ( $\mathrm{FEV}_{1}$ and Tiffeneau index), and low level of QL in the physical and psychological domains.

In conclusion, the patients with asthma and MetS have a more severe clinical course of asthma, with frequent exacerbations and uncontrolled asthma symptoms, low spirometry results and a low level of QL.

\section{Competing interests}

The authors declare that they have no competing interests.

\section{Acknowledgments}

This work was partially supported by the Council on Grants of the President of the Russian Federation for State Support of Young Scientists and Leading Scientific Schools (grant NSh 4994.2018.7).

\section{References}

1. Agrawal A, Mabalirajan U, Ahmad T, Ghosh B Emerging interface between metabolic syndrome and asthma. Am J Respir Cell Mol Biol. 2011;44(3):270-5. doi: 10.1165/ rcmb.2010-0141TR.

2. Tevetikova LN, Budnevsky AV, Provotorov VM, Filatova YI. Features of bronchial asthma clinical course against the background of oxidative stress inhibition. Lechashchij vrach. 2017;2:79. [Article in Russian].

3. World Health Organization. Asthma. Fact sheet. Updated April 2017. Available from: http://www.who.int/mediacentre/ factsheets/fs307/en/

4. Clinical guidelines. Asthma. Russian respiratory society, Pediatric respiratory society. 2016:76. [in Russian].

5. Federal clinical guidelines on asthma diagnostics and therapy. 2016. Available from: http://spulmo.ru/obshchestvo/ news/news-812/. [in Russian].

6. Roytberg GE. Metabolic syndrome. Moscow: MEDpressinform; 2007. [in Russian].

7. Lorenzo C, Williams K, J. Hunt K, M. Haffner S. The National Cholesterol Education Program-Adult Treatment Panel III, International Diabetes Federation, and World Health Organization Definitions of the Metabolic Syndrome as Predictors of Incident Cardiovascular Disease and Diabetes. Diabetes Care. 2007;30(1):8-13.

8. Sysoeva MS, Solov'eva AV, Nikiforova LV, Rakita DR. Influence of metabolic syndrome on the course of bronchial asthma. Rossijskij mediko-biologicheskij vestnik 
imeni akademika I.P. Pavlova. 2011;(4):100-105. [Article in Russian].

9. Brumpton B, Langhammer A, Romundstad P, Chen Y, Mai XM. General and abdominal obesity and incident asthma in adults: the HUNT study. Eur Respir J. 2013;41(2):323-9. doi: 10.1183/09031936.00012112.

10. Latysheva E.A, Gendlin GE, Storozhakov GI, Kurbacheva OM. Hypotensive therapy at patients with combination of hypertension and bronchial asthma. Arterial'naya gipertenziya. 2009;1:71-77. [in Russian].

11. Sideleva O, Suratt BT, Kendall E, William G, Richard E, Forgione P, et al. Obesity and asthma: an inflammatory disease of adipose tissue not the airway. Am J Respir Crit Care Med.2012;186(7):598-605. doi: 10.1164/rccm.201203-0573OC 12. Mineev VN, Lalaeva TM, Vasilıeva TS, Trofimov VI. Phenotype of bronchial asthma with obesity. Pul>monologiya. 2012;2:102-107. [Article in Russian].

13. Global strategy for asthma management and prevention (GINA, 2017 REPORT). Available from: file://C:/Users/ Admin/Downloads/wmsGINA-2017-main-report-final_ V2\%20(1).pdf.

14. The IDF consensus worldwide definition of the Metabolic Syndrome, 2006. Available from: file://C:/Users/Admin/ Downloads/IDF_Meta_def_final\%20(2).pdf. 